Research Article

\title{
How the Pregabalin (Lyrica) Administration as a Abuse Drug Can affects the Reproductive Health of male Wistar Rat
}

\author{
Nouf Bader Alduweesh*1 \\ ${ }^{1}$ Department of Zoology, Faculty of Science, Kuwait University, Kuwait, BSc. Department of Zoology, Faculty of Science, Cairo \\ University, Egypt, MSc \& PhD. Ministry of Education. \\ *Corresponding author's E-mail: noufalduweesh1@gmail.com
}

Received: 12-06-2021; Revised: 18-08-2021; Accepted: 26-08-2021; Published on: 15-09-2021.

\begin{abstract}
Drugs addiction considered a massive problem persist in diverse populations everywhere the world. Our work aimed to illustrate the correlation between drug addiction and reproductive function in an animal model, also the potential impact of pregabalin (Lyrica) intake on spermatozoa formation process and sexual hormone levels. In this study, we used 14 adult healthy rats that allocated into two groups $(n=7)$ as control and treated that orally administrated with pregabalin $(23.7 \mathrm{mg} / \mathrm{kg})$ for 30 subsequent days. Reproductive hormones, spermatozoa parameters (motility and morphology), lipid peroxidation (MDA), nitric oxide, total antioxidant activity, DNA damage and histopathological investigation were performed. The results revealed that pregabalin addiction had a harmful impact on the hypothalamus-pituitary-gonad axis of male rats through hindered hormones secretion, raised reactive oxygen species, affect antioxidant enzymes, triggered DNA damage and distorted testicular histology. Finally, we found that addiction of Lyrica caused adverse impact on the male reproductive health and subsequently affect fertility.
\end{abstract}

Keywords: Pregabalin (Lyrica), Abuse drug, Male, Wistar rat, Reproductive toxicity.

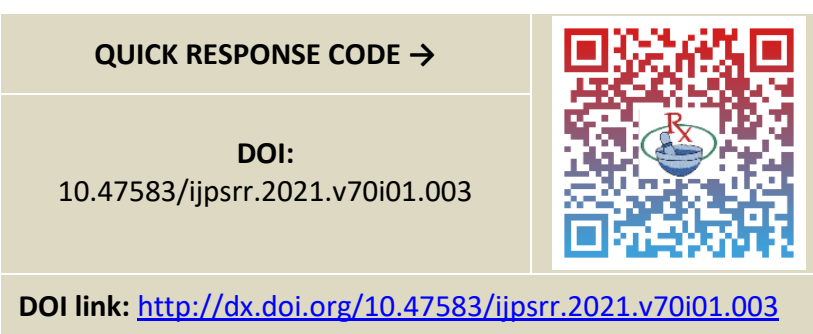

\section{INTRODUCTION}

T he genitourinary organs can be influenced by drugs, many studies investigate the impacts of drugs on this structure is of extraordinary significance. Several experimental works have shown that oral opium can diminish luteinizing hormone (LH), dihydrotestosterone, and follicle stimulating hormone (FSH), and can cause hypogonadism in $89 \%$ of users. The predominance of erectile brokenness and diminished libido is additionally significantly higher in sedate abusers ${ }^{1}$.

Pregabalin is an alkylated simple of c-aminobutyric acid (GABA) and basically linked to gabapentin ${ }^{2}$. In expansion, GABA mimetic properties have been appeared in rats ${ }^{3}$. A study by Grosshans et al. found that unlawful utilize of pregabalin was communal among opioid-addicted persons ${ }^{4,5}$. Lyrica is not a narcotic or an opioid. Lyrica is in a kind of medicines named anticonvulsants.

Various components can disrupt spermatogenesis progression and decrease sperm's property and amount. Effective spermatogenesis based on a multifaceted relation between endocrine, paracrine and autocrine components ${ }^{6,7}$. Obviously, many inherited illnesses might impede the spermatozoa formation mechanism. The non- genetic reasons of male infertility, oxidative stress (OS) coming about from overstated generation of reactive oxygen species (ROS) is maybe the foremost identified issue.

ROS are required for capacitation, the acrosome reaction and eventually fertilization; be that as it may, diminished removal and overproduction are capable to initiate DNA harm and imperfect membrane reliability of spermatozoa, in this manner coming about in decreased fertility capacity 7,8 . An extraordinary generation of reactive oxygen species (ROS) can be harming to the sperm cells. The spermatozoa plasma membrane contains enormous quantities of unsaturated fatty acids. Hence, it is vulnerable to peroxidative damage. The lipid peroxidation abolishes the constitute of lipid ground of spermatozoa membranes and distracts sperm's motility ${ }^{9,10}$.

The present study aimed to investigate the potential harmful effect of pregabalin (Lyrica) addiction on the male reproductive health and try to illustrate the exact mechanism through which the used drug can caused infertility and affect sperm function.

\section{MATERIALS AND METHODS}

\section{Animals}

14 male Wistar with the weight range of 200-220 g was obtained from National organization for drug control and research (NODCAR). The animals were reserved in an animal house for one week under well-ordered laboratory settings at temperature $22^{\circ} \mathrm{C} \pm 2^{\circ} \mathrm{C}$, humidity $(50 \%-60 \%)$ and $12 \mathrm{~h}$ in light and $12 \mathrm{~h}$ in dark with permitted admission to water and food. 


\section{Experimental design}

The practical work was agreed by the Cairo University, Faculty of Science Institutional Animal Care and Use Committee (IACUC) (Egypt), (CU/I/S/3/20). The rats were allocated into two groups as follows: group one (control), received distilled water and group two (treated), and administrated orally with abuse dose of pregabalin (Lryrica) $23.7 \mathrm{mg} / \mathrm{kg}$ for one month according to World Health Organization $2018{ }^{11}$ for four weeks day after day.

\section{Sperm collection}

After one month, the rats were sacrificed using an intraperitoneal injection of sodium pentobarbital (100 $\mathrm{mg} / \mathrm{kg}$ ). Then, testes, epididymis and seminal vesicle were collected, washed with saline, dried and weighted. The cauda part of the epididymis was used to evaluate sperm parameters. In each animal, right testes fixed in neutral $10 \%$ formalin for histopathological analysis and left one freeze at $-20^{\circ} \mathrm{C}$ for further investigation. Cauda epididymis were minced, and protected in a warm Petri dish containing $5 \mathrm{ml}$ physiological saline solution ( $\mathrm{Ph} \mathrm{7.4)}$ at $37^{\circ} \mathrm{C}$. The spermatozoa were permitted to disperse into the buffer ${ }^{12}$.

\section{Sperm count}

For calculating the sperm, $500 \mu \mathrm{L}$ of the sperm suspension was diluted (dilution of $1: 10$ ) with formaldehyde fixative ( $10 \%$ formalin in phosphate buffered saline). $10 \mu \mathrm{L}$ from the diluted solution was placed into a hemocytometer. Hemocytometer was situated in a moist chamber for 7 min. Hemocytometer was placed on the microscope stage. Then, the sperms at the four corners of the central square were counted ${ }^{13}$.

\section{Sperm morphology}

Eosin/ nigrosin stain was operated to evaluate spermatozoa morphology. One drop of eosin/nigrosin was added to the suspension and slightly mixed. The slides were then examined under the light microscope at $\times 400$. $A$ total of 300 spermatozoa were evaluated on each slide to find the anomalies of the head and tail ${ }^{14}$.

\section{Sperm high motility}

The sperm motility was measured through the light microscope at $\times 400$. One drop of sperm suspension was set on a glass slide. The number of the sperms with rapid progressive forward movement was computed and the percentages of high motile sperms were achieved ${ }^{15}$.

\section{Hormones profile}

Blood were harvested from the rats by cardiac puncture in clean tube, centrifuged at $3000 \mathrm{rpm}$ for $15 \mathrm{~min}$ to obtain sera and then were kept at $-20^{\circ} \mathrm{C}$ for hormones analysis. Quantitative determination of Testosterone $(\mathrm{T})$, folliclestimulating hormone (FSH) and luteinizing hormone ( $\mathrm{LH}$ ) level were measured using ELISA kits specific for rats (SunLong Biotech Co., LTD).

\section{Redox status}

Reactive oxygen species evaluated using reagent kits obtained from Bio Diagnostic (Egypt). Freeze testes minced in PBS $(1: 10 \mathrm{ml})$. The suspension was centrifuged at 3000 rpm for 20 minutes, and the supernatant was used to test MDA level by means of Satoh ${ }^{16}$, NO concentration based on Montgomery and Dymock ${ }^{17}$ and total antioxidant capacity as designated by Koracevic et al. ${ }^{18}$.

\section{Comet assay}

DNA injury was estimated using the single-cell gel electrophoresis technique ${ }^{19}$. The DNA damage were calculated through comet score software, in which the DNA \% in the tail, the tail length and the tail moment might be acquired.

\section{Histological examination}

For light microscopical investigation, the testes of two groups were fixed by immersion in $10 \%$ neutral formalin. All samples were relocated in $70 \%$ ethanol and then dehydrated in an ascending run of ethanol, cleared in xylol and embedded in paraffin. Five $\mu \mathrm{m}$ thick sections were yielded using a rotary microtome. Histological staining was performed with Ehrlich's hematoxylin and counterstained with aqueous eosin ${ }^{20}$. Microscopical examination and photographing of the histological sections were implemented with AmScope microscope.

\section{Statistical analysis}

Statistical analysis was achieved by the independent t-test to reveal mean and standard error mean of all examined parameters using Statistical Package for the Social Sciences (SPSS). The differences between control and treated group at significance level of $0.05(P<0.05)$.

\section{RESULTS}

\section{Effect of Lyrica on tissues weight}

The absolute and relative reproductive organs weights of different treated groups are showed in Table 1. Lyrica exposure triggered a reduction in in testes, epididymis and seminal vesicle weights.

Table 1: Showing effect of Lyrica on testes weight.

\begin{tabular}{|c|c|c|}
\hline Groups & Treated & Control \\
\hline Parameters & & $1.36 \pm 0.08$ \\
\hline Absolute right testes weight $(\mathrm{g})$ & $1.2 \pm 0.136$ & $0.508 \pm 0.032$ \\
\hline Relative right testes weight $(\%)$ & $0.496 \pm 0.49$ & $1.33 \pm 0.098$ \\
\hline Absolute left testes weight $(\mathrm{g})$ & $1.16 \pm 0.181$ & \\
\hline
\end{tabular}




\begin{abstract}
Relative left testes weight (\%)
Absolute right epididymis weight (g)

Relative right epididymis weight (\%)

Absolute left epididymis weight (g)

Relative left epididymis weight (\%)

Absolute seminal vesicle weight (g)

Relative seminal vesicle weight (\%)
\end{abstract}

\begin{tabular}{|c|c|}
\hline $0.48 \pm 0.071$ & $0.491 \pm 0.031$ \\
\hline $0.175 \pm 0.017$ & $0.183 \pm 0.016$ \\
\hline $0.072 \pm 0.006$ & $0.065 \pm 0.005$ \\
\hline $0.175 \pm 0.017$ & $0.183 \pm 0.016$ \\
\hline $0.072 \pm 0.006$ & $0.065 \pm 0.005$ \\
\hline $0.316 \pm 0.072$ & $1 \pm 0.143$ \\
\hline $0.316 \pm 0.072$ & $1 \pm 0.217$ \\
\hline
\end{tabular}

\section{Effect of Lyrica on reproductive hormones}

Lyrica administration revealed significant imbalance in the reproductive hormones' levels in comparison by control group. The testosterone, $\mathrm{LH}$ and FSH levels were decreased in the treated rats when compared with control group. Also treated group reveled non-significant increase in alkaline acid phosphate (ACP) in comparison with the control one (Table 3).

Table 3: Showing effect of Lyrica on reproductive hormones.

\begin{tabular}{|c|c|c|}
\hline Groups & Control & Treated \\
\hline Parameters & & \\
\hline Testosterone $(\mathrm{ng} / \mathrm{ml})$ & $0.456 \pm 0.044$ & $0.22 \pm 0.036^{*}$ \\
\hline FSH $(\mathrm{mlU} / \mathrm{ml})$ & $4.35 \pm 0.375$ & $3.05 \pm 0.028^{*}$ \\
\hline LH $(\mathrm{mlU} / \mathrm{ml})$ & $3.47 \pm 0.306$ & $2.55 \pm 0.028^{*}$ \\
\hline
\end{tabular}

Values are expressed as Mean \pm SEM. The statistical differences were analyzed by independent samples t-test. $*=\mathrm{P}<0.05$ compared with control.

\section{Effect of Lyrica on redox status}

Lyrica exposure increase the malonaldehyde (MDA) level non-significantly in comparison with the control group. Similarly, addiction of lyrica create a significant rise in content of nitric oxide (NO). Also, lyrica taken elevate the total antioxidant activity non-significantly as compared with the control group in all examined tissues (Table 4).

Table 4: Showing effect of Lyrica on ROS markers.

Figure 1: Showing effect of pregabalin on testes weight.

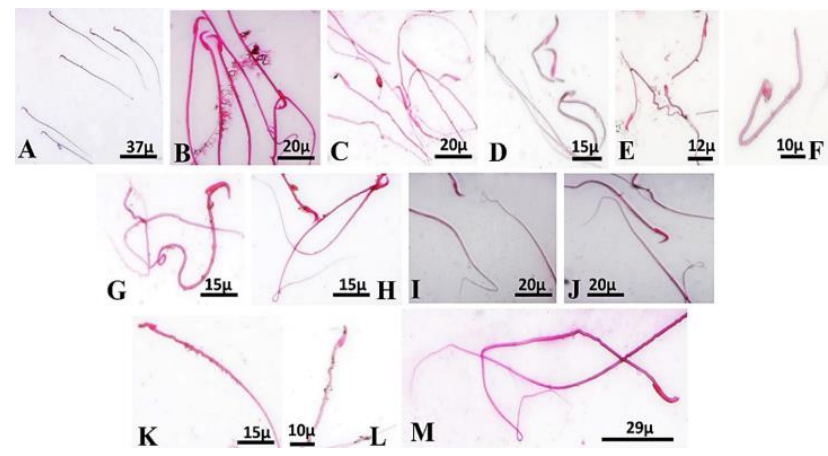

Values are expressed as Mean \pm SEM. The statistical differences were analyzed by independent samples t-test. $*=\mathrm{P}<0.05$ compared with control.

Figure 2: Showing effect of pregabalin on sperm morphology. A\& B: control. C-F: Amorphous head. G-J\&M: bent tail. K-M: sperm with Hook defect. 
Table 5: Showing effect of Lyrica DNA damage index.

\begin{tabular}{|c|c|c|}
\hline Groups & Control & Treated \\
\hline Parameters & & \\
\hline Comet \% & $8.65 \pm 0.375$ & $3.45 \pm 0.837^{*}$ \\
\hline Tail Length & $5.07 \pm 0.268$ & $12.61 \pm 0.827^{*}$ \\
\hline Tail DNA \% & $7.48 \pm 0.144$ & $8.04 \pm 0.575$ \\
\hline Tail Moment & $0.442 \pm 0.065$ & $1.012 \pm 0.024^{*}$ \\
\hline Olive Moment & $0.687 \pm 0.022$ & $1.32 \pm 0.28^{*}$ \\
\hline
\end{tabular}
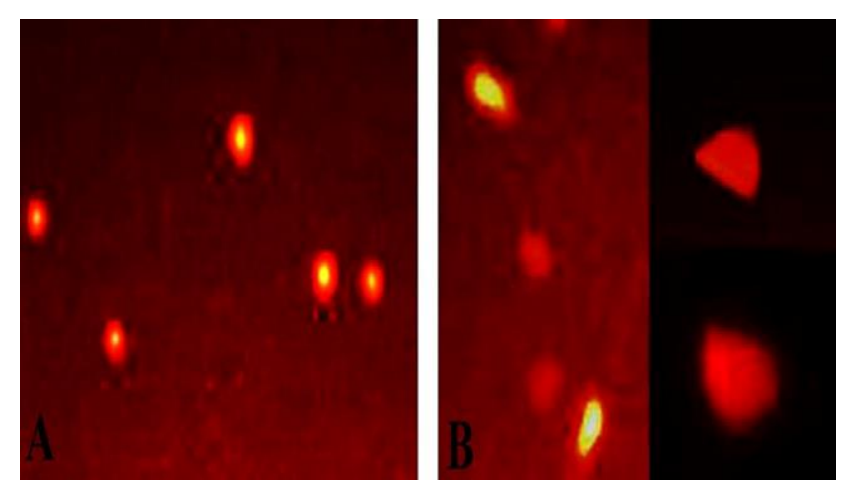

Figure 3: Showing effect of pregabalin on DNA. (A) Control and (B) Treated.

Values are expressed as Mean \pm SEM. The statistical differences were analyzed by independent samples t-test. $*=\mathrm{P}<0.05$ compared with control.

\section{Effect of Lyrica on DNA damage}

We used the comet assay (single cell gel electrophoresis) to inspect the influence of Lyrica on DNA by evaluating the DNA tail, tail length and tail moment in the examined tissue (Fig. 3 and Table 5). The treated group exposed to lyrica displayed a significant change in the comet parameters compared with the control rats except for Tail DNA \% showed insignificant increase as compared with the control group.

\section{Histopathological results}

Histological investigation of testis of control rat stained with H\&E presented standard form of seminiferous tubules and interstitial tissue. Each tubule was lined with stratified epithelium (germinal cells) and supportive Sertoli cells. The germinal cells were organized in several layers (spermatogenic cells). Leydig cells were found between stroma connective tissue. Animals taken Lyrica displayed different histopathological alterations. The seminiferous tubules have irregular outline, degenerated tubules were noticed with absence of spermatozoa. Most of the seminiferous tubules revealed injured and disordered spermatogenesis cells and the impaired germ cells were exfoliated in the lumen. Furthermore, nonexistence of spermatozoa was obviously documented. Plentiful spermatocytes seemed with pyknotic nuclei and many vacuoles were observed in the seminiferous tubules. Some seminiferous tubules be seen cracked (Fig. 4).
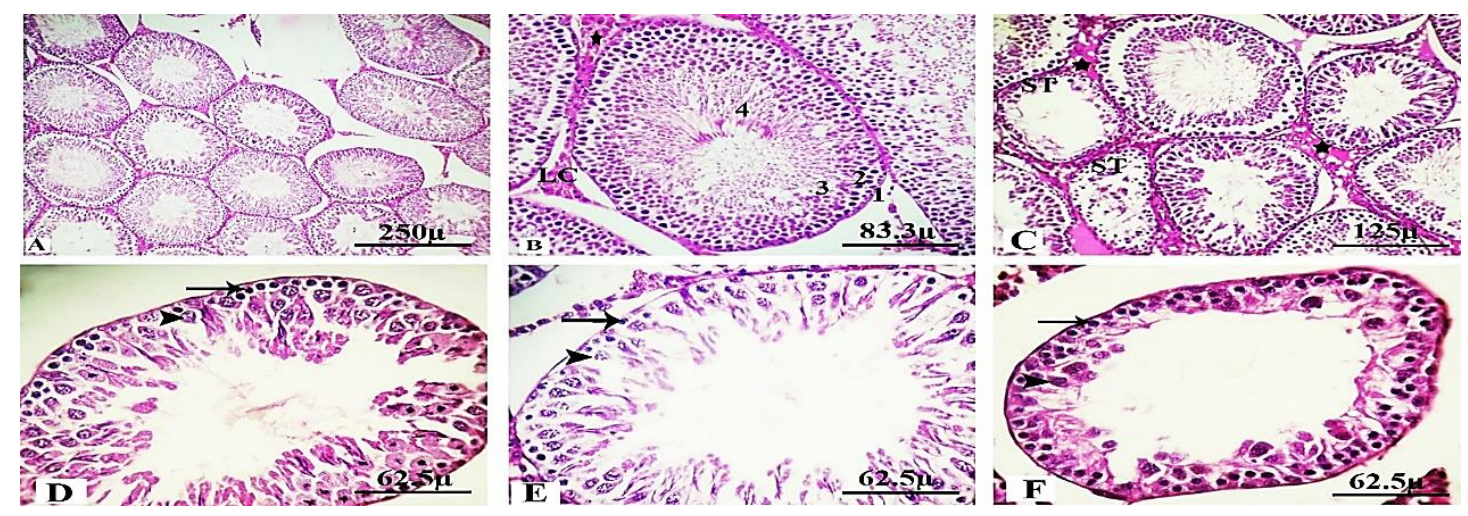

Figure 4: Showing effect of pregabalin on histology. Photomicrographs of a section in the testis of control albino rats (A\&B); the normal histological structure, multiple number of seminiferous tubules (ST) lined by many kinds of germinal epithelium (spermatogonia 1, spermatocyte 2, spermatid 3). Mature sperms in the lumen (4) and the interstitial tissue $\left({ }^{*}\right)$ in between the tubules, which contain Leydig cells (LC). Treated group; (C) degenerated and disorganized seminiferous tubule (ST) without spermatozoa and vacuoles between interstitial tissue $\left({ }^{*}\right)$. (D-F) pyknotic spermatogonia (arrow) and primary spermatocytes with karyolysis signs (arrowhead), wide lumen devoid of sperms.

\section{DISCUSSION}

In this study, we investigated the correlation between drug abuse and sexual performance also the impending influence of pregabalin (Lyrica) intake on spermatozoa formation and reproductive hormones activity.
Drugs addiction considered a massive problem persist in diverse populations everywhere the world. Lyrica is not a narcotic or an opioid. Lyrica is in a kind of medicines named anticonvulsants.

The outcomes showed that pregabalin (Lyrica) reduced sperm motility, normal sperm morphology, augmented testicular DNA damage, and prompted histopathological 
alterations in testicular tissue. These harmful impacts have been complemented by provoked oxidative stress in testicular tissue and the change of serum hormone levels that participate a part in the spermatogenesis progression.

Some findings have implied that the drug misuse have destructively influence male fertility, with an effect on hypothalamus-pituitary-gonadal axis, spermatogenesis, and sperm function, Leydig cells, Sertoli cells and in testicular tissues ${ }^{7,21}$.

Organ weights are susceptible indicators to reveal toxicity after chemical exposure ${ }^{22}$. Tissue weight change mirror the distractions of the reproductive system functions ${ }^{23}$. In our study, significant decreasing in absolute and relative testis and epididymis weights after pregabalin (Lyrica) intake were not detected.

The testicular tissue weights are related with the Sertoli cells number and spermatozoa formation consequently the testis size is indication of the germinal cells number in the testis ${ }^{12}$. This might be as a result of free radicals' creation and ROS by pregabalin (Lyrica) and effect of these detrimental elements on testis susceptible cells.

Spermatozoa motility, and morphology are pointers used to estimate semen quality, testicular function and verify reproductive toxicity ${ }^{23}$. A decline in sperm motility and sperm morphology abnormalities are a significant parameter of chemical caused infertility ${ }^{24,25}$.

Regulatory authorities like EPA, FDA, OECD, WHO, and ICH underline the significance of the sperm head, sperm midpiece and tail abnormalities especially twisted tail and bent/spiral tail are related to infertility ${ }^{25,26}$.

$\mathrm{FSH}, \mathrm{LH}$, and testosterone have parts in male reproductive functions conservation and so, hormone levels determination is essential in reproductive toxicity reports ${ }^{25}$. It is proven that $\mathrm{LH}$ and FSH are released below the regulator hypothalamic gonadotropin-releasing hormone from the anterior pituitary. LH motivates the testosterone secretion from Leydig cells, and testosterone is mandatory for secondary sexual appearances and spermatogenesis. FSH controls the spermatozoa production in Sertoli cells 25,27 . The hypothalamic-pituitary gonadal axis can be influenced by several agents. Chemicals comprising drugs can lessen fertility and cause infertility by disordering the ordinary function of this axis ${ }^{28}$. It has been revealed that antiepileptic drugs affect hypothalamic pituitary gonadal axis and trigger reproductive malfunction ${ }^{29,30}$. In our study, fallen serum $\mathrm{FSH}, \mathrm{LH}$, and testosterone levels were detected after drug administration. Previous studies presented that LH and FSH levels were not changed ${ }^{25,31}$.

In addition, a reduction of testosterone level is associated to the spermatogenic cell damage and spermatogenesis distraction, and subsequently initiate reproductive power disordered $25,27,28$.

Opioids play on the hypothalamic-pituitary axis by hindering the $\mathrm{GnRH}$ discharge, that suppress FSH and $\mathrm{LH}$ release accordingly cause spermatogenesis impairment and decline testosterone concentrations ${ }^{32}$. Vuong et al. ${ }^{33}$ stated that opioid- convinced hypogonadism. Other articles imply that sperm concentration and quality are damaged in opioid users, augmented DNA fragmentation level and lowered catalase (CAT) and superoxide dismutase (SOD) activity were seen in addict men competed to healthy persons ${ }^{7,34}$.

Pregabalin drug decreases serotonin discharge in the synaptic cleft. Meanwhile serotonin is the required mediator in melatonin creation, thus causing melatonin reduction. Melatonin is an antioxidant and has an important role in defending the testicular tissue against damage induced by ROS. Low melatonin activity causing lessening in testosterone synthesis and secretion by lessening the glutathione peroxidase (GPx) enzyme ${ }^{35,36}$.

Prior paper presented that the pituitary gonadotropins, serum FSH, LH, and PRL hormone levels reduced using two doses of pregabalin, these clarifications are arrangement with our study, and is due to the antiepileptics (ADEs) may has an effect on the gonadal level ${ }^{37,38}$, Pregabalin (PGB) has the ability to hinder the central nervous system activity, that controls physiological and behavioral consequences correlated with normal reproductive performance through hormonal signals ${ }^{38,39}$.

Harden and Pennell ${ }^{40}$ indicated that ADEs may intermingle with gonads. Since PGB drug blockade calcium channels, that analogous neurochemical mechanisms are involved in the interaction of these drugs with hypothalamic neurohormones synthesis as gonadotropin-releasing hormone $(\mathrm{GnRH})$, so PGB may be affects hypothalamus because $\mathrm{GnRH}$ discharge from neurons is based on the depolarization - caused influx of extracellular calcium and because PGB effects on Ca2+ channels by blockading or inhibiting $\mathrm{Ca} 2+$ influx on hypothalamus that is susceptible to change the $\mathrm{GnRH}$ pulsations and trigger reduction in $\mathrm{LH}$ and FSH levels ${ }^{38,41}$.

Findings demonstrated that testosterone clearly affects the Sertoli cells. Sertoli cells providing nutrients for dividing spermatogenic cells. They produce many growth factors and transferring proteins which has a critical role in cell division and spermatozoa formation ${ }^{36}$. Concerning the testosterone role on spermatogenesis, reduction in this hormone secretion induced sperm density decrease. Mammalian spermatozoa has high unsaturated fatty acids quantity that are main substrates in oxidation. In normal situations antioxidant mechanisms are participate in reproductive tissues and inhibit oxidative injure in different gonadal cells and developed sperm ${ }^{42}$. The previous reports reveled that free radical's creation directly disturbs sperm proliferation, activity and fertility ${ }^{36}$.

Hypothalamus release Luteinizing hormone releasing hormone (LHRH) that initiates the secretion of $\mathrm{LH}$ from pituitary gland then testosterone releasing from the testes. We did not identify if the decreased LH was because of pituitary malfunction or the decreasing LHRH release in 
the treated group. It is probable that $\mathrm{LHRH}, \mathrm{LH}$, and testosterone were distressed by the PGB ${ }^{1,43}$.

The oxidative stress induce lipid peroxidation affects semen quality, and inducing male infertility 25,44,45. Oxidative stress induced a reduction in intracellular ATP levels, apoptotic factors creation resulting in mitochondrial membrane disturbance, protein phosphorylation disorder, rise in membrane permeability, and spermicidal molecules formation, impairment of acrosome membrane so reduces semen quality, concentration, motility and morphology ${ }^{44}$. Moreover, antioxidant defense mechanism deficiency participates to the sperm vulnerability ${ }^{25,46}$. In our study, reduced total antioxidant activity levels and increased MDA and NO levels were observed following PGB administration signifying that PGB induced oxidative stress in testicular tissue.

Nitric oxide has an essential role in sperm physiology and have many undesirable effects on hypothalamic-pituitarytesticular axis ${ }^{47}$. There is a correlation between nitric oxide and sperm acrosome and tail. Nitric oxide can reduce the sperm motility by decreasing ATP level ${ }^{48}$. Nitric oxide can damage sperm mitochondrial membrane, thus releasing $C$ chromosome, initiating caspase cascade activity and promoting apoptosis ${ }^{12,15}$.

In the study of Daniel et al., severe morphologic variations of the sperms were seen in microscopic analysis of the semen of addicts, which verifies the outcomes of the existing study ${ }^{12,49}$.

Our results showed significant initiation of oxidative stress after pregabalin exposure. This comes in accordance with the results of Kamel ${ }^{50}$ who explored the effect of chronic oral pregabalin administration for 90 days on the rat brains and stated significant decline in SOD and CAT in pregabalin administered groups ${ }^{51}$.

Sperm DNA integrity is a clue of the sperm reproductive power ${ }^{52}$. So, the DNA's structural integrity was examined to estimate sperm function. The neutral comet assay is simpler, sensitive and accurate method in clarifying DNA damage double-strand breaks in human sperm ${ }^{25,53}$.

In this study tail length, DNA percentage in tail and olive tail moment were recorded to evaluate genotoxic impact of the PGB. These parameters were particularly crucial to determine the DNA damage severity after exposure to genotoxic environmental agent ${ }^{54}$. Many studies stated that tail moment is a clearer value to evaluate DNA damage ${ }^{25,55}$.

Thus, PGB generated DNA damage seen in our study may be due to oxidative stress, promoting DNA histone modification. Additionally, sperm head morphology is an indirect mark of mutagenic effects induced by chemical exposure. The preceding report found a confident association between sperm head abnormalities and DNA damage, and it was discussed that imperfections in sperm head morphology developed from genetic material damage ${ }^{25,56}$. Here sperm head abnormalities boosted by PGB intake reflected DNA damaging.

\section{CONCLUSION}

Based on the preceding elucidation we imply that Lyrica may be create imbalance redox status by producing reactive oxygen species and nitrogen with low antioxidant power that initiating cell destruction through interaction with the lipid of cell membranes, nucleic acid and proteins which influences cells signaling pathways that controlling programmed cell death (apoptosis and necrosis) and cell proliferation finally causing reproductive hormones levels and histopathological alternation.

Acknowledgements: This work was supported by Zoology Department- Faculty of Science- Cairo University.

\section{REFERENCES}

1. Ahmadnia H, Akhavan Rezayat A, Hoseyni M, Sharifi N, Khajedalooee M, Akhavan Rezayat A. Short-Period Influence of Chronic Morphine Exposure on Serum Levels of Sexual Hormones and Spermatogenesis in Rats. NephroUrology Monthly. 2016; 8(4).

2. Montgomery S, Emir B, Haswell H, Prieto R. Long-term treatment of anxiety disorders with pregabalin: a 1 year open-label study of safety and tolerability. Curr Med Res Opin. 2013; 29(10): 1223-30.

3. de Guglielmo G, Cippitelli A, Somaini L, Gerra G, Li H, Stopponi $S$, et al. Pregabalin reduces cocaine selfadministration and relapse to cocaine seeking in the rat. Addiction Biology. 2012; 18(4): 644-53.

4. Grosshans $M$, Lemenager $T$, Vollmert $C$, Kaemmerer $N$, Schreiner R, Mutschler J, et al. Pregabalin abuse among opiate addicted patients. Eur J Clin Pharmacol. 2013; 69(12): 2021-5.

5. Schjerning $O$, Rosenzweig $M$, Pottegård $A$, Damkier $P$, Nielsen J. Abuse potential of pregabalin: A systematic review: A systematic review. CNS Drugs. 2016; 30(1): 9-25.

6. Tournaye $H$, Krausz $C$, Oates RD. Novel concepts in the aetiology of male reproductive impairment. Lancet Diabetes Endocrinol. 2017; 5(7): 544-53.

7. Sansone A, Di Dato C, de Angelis C, Menafra D, Pozza C, Pivonello $\mathrm{R}$, et al. Smoke, alcohol and drug addiction and male fertility. Reprod Biol Endocrinol. 2018; 16(1): 3.

8. Lombardo F, Sansone A, Romanelli F, Paoli D, Gandini L, Lenzi A. The role of antioxidant therapy in the treatment of male infertility: an overview. Asian J Androl. 2011; 13(5): $690-7$.

9. Alahmar A. Role of oxidative stress in male infertility: An updated review. Journal of Human Reproductive Sciences. 2019; $12(1): 4$.

10. Villaverde AISB, Netherton J, Baker MA. From past to present: The link between reactive oxygen species in sperm and male infertility. Antioxidants (Basel). 2019; 8(12): 616.

11. World Health Organization (WHO). Critical Review Report: Pregabalin. 2018: 1-33.

12. Jalili C, Salahshoor M, Haghjoo M, Roshankhah S, Makalani F. Effect of thymoquinone on reproductive parameter in 
morphine-treated male mice. Adv Biomed Res. 2018; 7(1): 18.

13. Salahshoor MR, Khazaei M, Jalili C, Keivan M. Crocin improves damage induced by nicotine on $\mathrm{A}$ number of reproductive parameters in male mice. Int J Fertil Steril. 2016; 10(1): 71-8.

14. Jalili C, Salahshoor MR, Naderi T. The effect of hydroalcoholic extract of P. crispum on sperm parameters, testis tissue and serum nitric oxide levels in mice. Adv Biomed Res. 2015; 4(1): 40.

15. Jalili C, Ahmadi S, Roshankhah S, Salahshoor M. Effect of Genistein on reproductive parameter and serum nitric oxide levels in morphine-treated mice. Int J Reprod Biomed (Yazd). 2016; 14(2): 95-102.

16. Satoh K. Clinica Chimica Acta. 1978; 90: 37.

17. Montgomery HAC, Dymock JF. Analyst. 1961; 86: 414.

18. Koracevic D, Koracevic G, Djordjevic V, Andrejevic S, Cosic $\mathrm{V}$. Method for the measurement of antioxidant activity in human fluids. J Clin Pathol. 2001; 54(5): 356-61.

19. Nandhakumar S, Parasuraman S, Shanmugam MM, Rao KR, Chand $\mathrm{P}$, Bhat BV. Evaluation of DNA damage using singlecell gel electrophoresis (Comet Assay). J Pharmacol Pharmacother. 2011; 2(2): 107-11.

20. Bancroft JD, Gamble M. Theory and Practice of Histological Techniques. 6th ed. Edinburgh: E.P. Churchill Livingstone. 2002.

21. Plessis SS, Agarwal A, Syriac A. Marijuana, phytocannabinoids, the endocannabinoid system, and male fertility. J Assist Reprod Genet. 2015; 32(11): 157588.

22. Kong L, Tang M, Zhang T, Wang D, Hu K, Lu W, et al. Nickel nanoparticles exposure and reproductive toxicity in healthy adult rats. Int J Mol Sci. 2014; 15(11): 21253-69.

23. Jayachandra $\mathrm{S}, \mathrm{Ng} \mathrm{A}$. Possible toxic effect of antihypertensive drug olmesartan on male reproductive system of rat. Int J Basic Clin Pharmacol. 2013; 2(1): 83.

24. Toman R, Hluchy S, Massanyi P, Lukac N, Adamkovicova M, Cabaj $M$, et al. Selenium and cadmium tissue concentrations and the CASA sperm motility analysis after administration to rats. Am J Anim Vet Sci. 2014; 9(4): 194202.

25. Baysal M, Ilgin S, Kilic G, Kilic V, Ucarcan S, Atli O. Reproductive toxicity after levetiracetam administration in male rats: Evidence for role of hormonal status and oxidative stress. PLOS ONE. 2017; 12(4).

26. Svalheim S, Sveberg L, Mochol M, Taubøll E. Interactions between antiepileptic drugs and hormones. Seizure. 2015; 28: $12-7$.

27. Wisniewski P, Romano RM, Kizys MM, Oliveira KC, Kasamatsu T, Giannocco G, et al. Adult exposure to bisphenol A (BPA) in Wistar rats reduces sperm quality with disruption of the hypothalamic-pituitary testicular axis. Toxicology. 2015; 329: 1-9.

28. Lin J-F, Lin Y-H, Liao P-C, Lin Y-C, Tsai T-F, Chou K-Y, et al. Induction of testicular damage by daily methamphetamine administration in rats. Chin J Physiol. 2014; 57(1): 19-30.
29. Andretta R, Okada F, Paccola C, Stumpp T, de Oliva S, Miraglia S. Carbamazepine-exposure during gestation and lactation affects pubertal onset and spermatic parameters in male pubertal offspring. Reproductive Toxicology. 2014; 44: 52-62.

30. Kumar S, Kaur G. Second generation anti-epileptic drugs adversely affect reproductive functions in young nonepileptic female rats. Eur Neuropsychopharmacol. 2014; 24(10): 1709-18.

31. Taubøll E, Gregoraszczuk EL, Wojtowicz AK, Milewicz T. Effects of levetiracetam and valproate on reproductive endocrine function studied in human ovarian follicular cells. Epilepsia. 2009; 50(8): 1868-74.

32. Fronczak $\mathrm{CM}$, Kim ED, Barqawi $\mathrm{AB}$. The insults of illicit drug use on male fertility. J Androl. 2012; 33(4): 515-28.

33. Vuong C, Van Uum SHM, O'Dell LE, Lutfy K, Friedman TC. The effects of opioids and opioid analogs on animal and human endocrine systems. Endocr Rev. 2010; 31(1): 98132.

34. Safarinejad MR, Asgari SA, Farshi A, Ghaedi G, Kolahi AA, Iravani $S$, et al. The effects of opiate consumption on serum reproductive hormone levels, sperm parameters, seminal plasma antioxidant capacity and sperm DNA integrity. Reprod Toxicol. 2013; 36: 18-23.

35. El-Sisy GA, Abdel-Razek AMA, Younis AA, Ghallab AM, Abdou MSS. Effect of dietary zinc or Selenium supplementation on some reproductive hormone levels in male Baladi Goats. Global Veterinaria. 2008; 2: 50-6.

36. Bostanian S, Shariati M, Zamanpoor M. Effect of Pregabalin on Pituitary - Gonad Axis and Testis Histological Changes in Adult Rat. J. Appl. Environ. Biol. Sci. 2016; 6(3): 165-171.

37. Sneha R, Sharangouda J, Ravikumar J, Vijaykumar B, Saraswati B. Study of effect of Phenobarbitone on ovarian and hormonal profile of albino rats. Recen Adva Pharmaceul Sci Res. 2012; 1(2): 81-91.

38. Tawfeeq EN, Yanzeel JH, Fakhrildi MB, Fanaei H, Khayat S, Halvaei I, et al. Effects of Pregabalin Drug on Level of Reproductive Hormones, Sexual Activity, Number and Weight of Offspring in Female Albino Rats. IJSR. 2017; 6(8): 103-10.

39. Uchida S, Kagitani F. Autonomic nervous regulation of ovarian function by noxious somatic afferent stimulation. J Physiol Sci. 2015; 65(1): 1-9.

40. Harden CL, Pennell PB. Neuroendocrine considerations in the treatment of men and women with epilepsy. Lancet Neurol. 2013; 12(1): 72-83.

41. Lason W, Dudra-Jastrzebska M, Rejdak K, Czuczwar S. Basic mechanisms of antiepileptic drugs and their Pharmacokinetic/pharmaco- dynamic interactions: an update. Pharmacol Reports. 2011; 63: 271- 292.

42. Mirfard $M$, Johari $H$, Mokhtari $M$, Hematkhah V, Jamali $H$, Allahverdi Gh. The Effect of Hydro-Alcoholic Garlic Extract on Testis Weight and Spermatogenesis in Mature Male Rats under Chemotherapy with Cyclophosphamide. Journal of Fasa University of Medical Sciences. 2011; 3(1): 67-74.

43. Ghowsi M, Yousofvand N. Impact of morphine dependency and detoxification by methadone on male's rat 
reproductive system. Iran J Reprod Med. 2015; 13(5): 27582.

44. Fanaei $\mathrm{H}$, Khayat $\mathrm{S}$, Halvaei I, Ramezani $\mathrm{V}$, Azizi $\mathrm{Y}$, Kasaeian A, et al. Effects of ascorbic acid on sperm motility, viability, acrosome reaction and DNA integrity in teratozoospermic samples. Iran J Reprod Med. 2014; 12(2): 103-10.

45. Giribabu N, Kumar KE, Rekha SS, Muniandy S, Salleh N. Chlorophytum borivilianum (Safed Musli) root extract prevents impairment in characteristics and elevation of oxidative stress in sperm of streptozotocin- induced adult male diabetic Wistar rats. BMC Complement Altern Med. 2014; 14(291).

46. Lewis SEM, John Aitken R, Conner SJ, luliis GD, Evenson DP, Henkel $R$, et al. The impact of sperm DNA damage in assisted conception and beyond: recent advances in diagnosis and treatment. Reprod Biomed Online. 2013; 27(4): 325-37.

47. Pinilla L, González LC, Tena-Sempere M, Bellido C, Aguilar E. Effects of systemic blockade of nitric oxide synthases on pulsatile $\mathrm{LH}$, prolactin, and $\mathrm{GH}$ secretion in adult male rats. Horm Res Paediatr. 2001; 55(5): 229-35.

48. Weinberg JB, Doty E, Bonaventura J, Haney AF. Nitric oxide inhibition of human sperm motility. Fertil Steril. 1995; 64(2): 408-13.

49. Daniell HW. Hypogonadism in men consuming sustainedaction oral opioids. The Journal of Pain. 2002; 3(5): 377-84.

50. Kamel MA.Study on DNA damage and oxidative stress and some biochemical alterations of long-term administration of alpha-2 delta (A2- $\Delta$ ) ligand pregabalin and the possibility of Zingiber officinale in ameliorating these effects in rats. World J Pharm Res.2016; 5: 1528-1545.

51. Taha SHN, Zaghloul HS, Ali AAER, Gaballah IF, Rashed LA, Aboulhoda BE. The neurotoxic effect of long-term use of high-dose Pregabalin and the role of alpha tocopherol in amelioration: implication of MAPK signaling with oxidative stress and apoptosis. Naunyn Schmiedebergs Arch Pharmacol. 2020; 393(9): 1635-48.

52. Khan $\mathrm{S}$, Jan $\mathrm{MH}$, Kumar D, Telang AG. Firpronil induced spermotoxicity is associated with oxidative stress, DNA damage and apoptosis in male rats. Pestic Biochem Physiol. 2015; 124: 8-14.

53. Chi H-J, Chung D-Y, Choi S-Y, Kim J-H, Kim G-Y, Lee J-S, et al. Integrity of human sperm DNA assessed by the neutral comet assay and its relationship to semen parameters and clinical outcomes for the ivf-et program. Clinical and Experimental Reproductive Medicine. 2011; 38(1): 10.

54. Møller P, Loft S, Ersson C, Koppen G, Dusinska M, Collins A. On the search for an intelligible comet assay descriptor. Front Genet. 2014; 5: 217.

55. Rasool EA, Abdul-Rasheed OF, AL-Hashimi AF. Comparison Between Different DNA and Conventional sperm parameters in Infertile Men, Al-kindy Col Med. J. 2012; $8(2): 40-7$.

56. Trivedi PP, Kushwaha S, Tripathi DN, Jena GB. Evaluation of male germ cell toxicity in rats: correlation between sperm head morphology and sperm comet assay. Mutat Res. 2010; 703(2): 115-21.

Source of Support: The author(s) received no financial support for the research, authorship, and/or publication of this article.

Conflict of Interest: The author(s) declared no potential conflicts of interest with respect to the research, authorship, and/or publication of this article.

For any question relates to this article, please reach us at: editor@globalresearchonline.net New manuscripts for publication can be submitted at: submit@globalresearchonline.net and submit_ijpsrr@rediffmail.com 